SSCL-624

\title{
Measurements of Ground Motion and SSC Dipole Vibrations
}

\author{
V. V. Parkhomchuk, * V. D. Shiltsev,* and H. J. Weaver
}

Superconducting Super Collider Laboratory ${ }^{\dagger}$

2550 Beckleymeade Ave.

Dallas, TX 75237

June 1993

"Guest Scientist from Budker Institute of Nuclear Physics, Novosibirsk, Russia.

† Operated by the Universities Research Association, Inc., for the U.S. Department of Energy under Contract No. DE-AC35-89ER40486. 


\title{
Measurements of Ground Motion and SSC Dipole Vibrations
}

\author{
V. V. Parkhomchuk, V. D. Shiltsev, and H. J. Weaver
}

\begin{abstract}
The results of seismic ground measurements at the Superconducting Super Collider (SSC) site and investigations of vibrational properties of superconducting dipoles for the SSC are presented. Spectral analysis of the data obtained in the large frequency band from $0.05 \mathrm{~Hz}$ to $2000 \mathrm{~Hz}$ is done. Resonant behavior and the dipole-to-ground transform ratio are investigated. The influence of measured vibrations on SSC operations is considered.
\end{abstract}




\subsection{INTRODUCTION}

Vibrations of the magnetic elements of the Superconducting Super Collider (SSC) can seriously jeopardize useful operation of the machine. Tolerable levels of vibrations for the SSC are at least a few orders of magnitude tighter than those for the largest existing hadron accelerators such as the Tevatron and SppS (CERN), because the transverse emittance of the beam will be about 100 times smaller and the circumference will be about 10 times larger at the SSC than for those smaller machines. A larger circumference means lower revolution and betatron frequencies-dangerous because of the rapid increase of vibrations at lower frequencies-and more magnetic elements in the rings, which can disturb the ideal motion of the beams.

Vibration effects on collider performance have been studied in several works, ${ }^{1-4}$ and it was found that depending on the frequency of the noise, one can distinguish two anechinisms of beam perturbation. At low frequencies (much less than the revolution frequency), the noise produces a distortion of the closed orbit of the beam. High-frequency noises-especially at frequencies near a fractional part of the betatron oscillation frequency $(700-1000 \mathrm{~Hz})$ at the SSC-cause direct transverse emittance growth. The following figures will give an idea of the seriousness of the issue:

1. The acceptable level of uncorrelated low-frequency motion of a single SSC quadrupole is approximately $0.1-0.3 \mu \mathrm{m} ; 3$

2. High-frequency turn-to-tum jitter of every quad with an amplitude of approximately $10^{-4} \mu \mathrm{m}$ will cause emittance doubling after only $20 \mathrm{~h} .^{3,4}$ (Damping time due to synchrotron radiation in the SSC is about 24 h.)

These figures should impress not only accelerator scientists but geophysicists as well. Measurement of such small vibrations is a rather complicated task. One can guess that the SSC beam will be the largest sensitive device ever built from the point of view of seismic vibrations.

Therefore, it was necessary to measure ground vibrations at first and then vibrations of magnetic elements over an extremely large frequency range from a few kilohertz to fractions of a hertz or to the lowest possible frequency. Experimental investigation of underground vibrations at the SSC site at frequencies of 1-100 $\mathrm{Hz}$ was made by The Earth Technology Corporation of Long Beach, CA, in 1989.5 Very detailed analysis was done, but the most interesting frequencies in the kilohertz range and the most powerful vibrations at frequencies below $1 \mathrm{~Hz}$ were not investigated. The Vibrational Workshop held at the SSC Laboratory in February 1992 also emphasized the lack of information about these important regions. ${ }^{6}$

This paper covers results of our seismic ground measurements at the SSC site and our measurement of vibrations of the SSC dipole in the extremely large frequency band of 0.05-2000 Hz. Additional highprecision seismic equipment from Budker INP (Novosibirsk, Russia) allowed us to obtain useful data up to frequencies 20 times larger and 20 times lower than those previously investigated.

In Section 2.0 we describe equipment, hardware, data processing, and conditions under which measurements were made. Principal results of measurements, the discussion, and comparison with other data are presented in Section 3.0. Section 4.0 is devoted to estimations of predicted beam motion in the SSC arcs. Further experiments, development, plans, and main conclusions are summarized in Section 5.0.

\subsection{EXPERIMENTAL CONSIDERATIONS}

Seismological equipment included three types of gauges: SM-3KV, TA-2, and Dytran. The first two were carried from the Budker INP in accordance with inter-laboratory agreement 92-W-11138, Attachment 26, and had been previously tested in vibrational studies for linear collider VLEPP7 and Novosibirsk B-Factory VEPP-5.8

Commercial velocimeter SM-3KV was modified to extend the frequency band up to $0.05-100 \mathrm{~Hz}$. The proper pendulum period of the probe is $2 \mathrm{~s}$. A special electrical feedback system modifies raw signal from 
the coil of the pendulum, which vibrates in the magnetic field system; thus, the output signal is proportional to the the velocity of vibrations without resonance, emphasizing the proper frequency. The probe allows us to measure vertical as well as horizontal vibrations after some simple mechanical transformations. During the investigations two probes in the vertical variant were used, with both calibrated in the working frequency range. Results of the calibration are presented in Figure 1 . The difference in the sensitivities of the two probes is less than $10 \%$. The mass of the probe is about $6 \mathrm{~kg}$, and its size is $10 \mathrm{~cm} \times 10 \mathrm{~cm} \times 20 \mathrm{~cm}$. Power spectra of noises of the probe and the usual ground vibration signals (made in Budker INP) are shown in Figure 2. One can see that the signal-to-noise power ratio exceeds 10 in the working frequency range.

TA-2 probes are newly developed piezoelectric probes manufactured by the Moscow Institute of Earth Physics especially for high-precision measurements at the Budker INP accelerators. Two probes were used in the measurements, each of which allows us to measure accelerations in three orthogonal directions simultaneously. The sensitivity of each channel is $0.5 \mathrm{~V} /\left(\mathrm{m} / \mathrm{s}^{2}\right)$ for vertical vibrations in the frequency band of $10-2000 \mathrm{~Hz}(3 \mathrm{~dB}$ level). Differences between channels and between probe sensitivities do not exceed 5\%. The dynamic range of the probe determined from proper noises is $100 \mathrm{~dB}$ relative to the acceleration of gravity. The mass of the probe is about $2 \mathrm{~kg}$, and its size is $6 \mathrm{~cm} \times 6 \mathrm{~cm} \times 15 \mathrm{~cm}$.

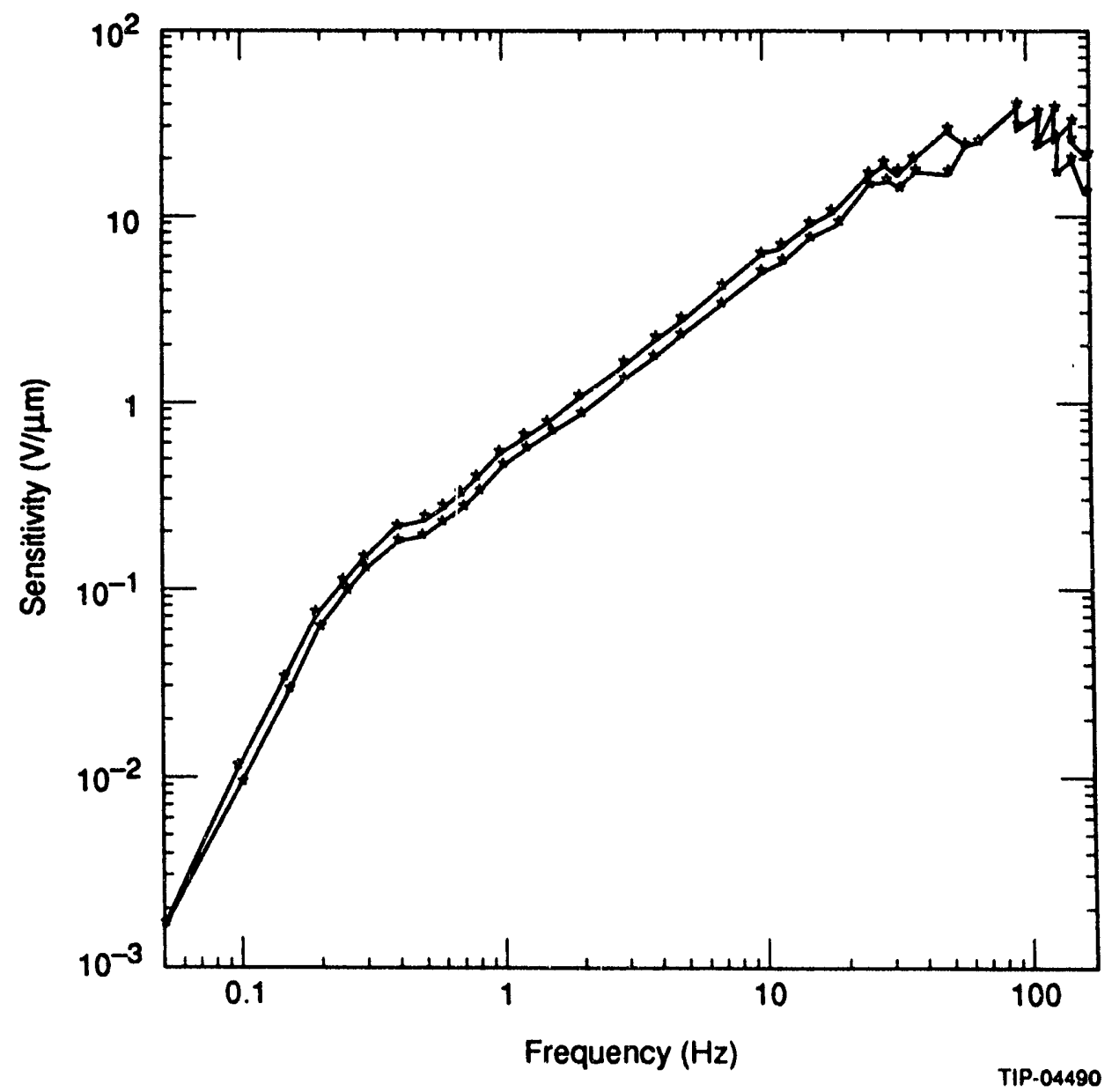

Figure 1. Callbration Curve of SM-3KV Probes (No. 1112 and No. 1440). 


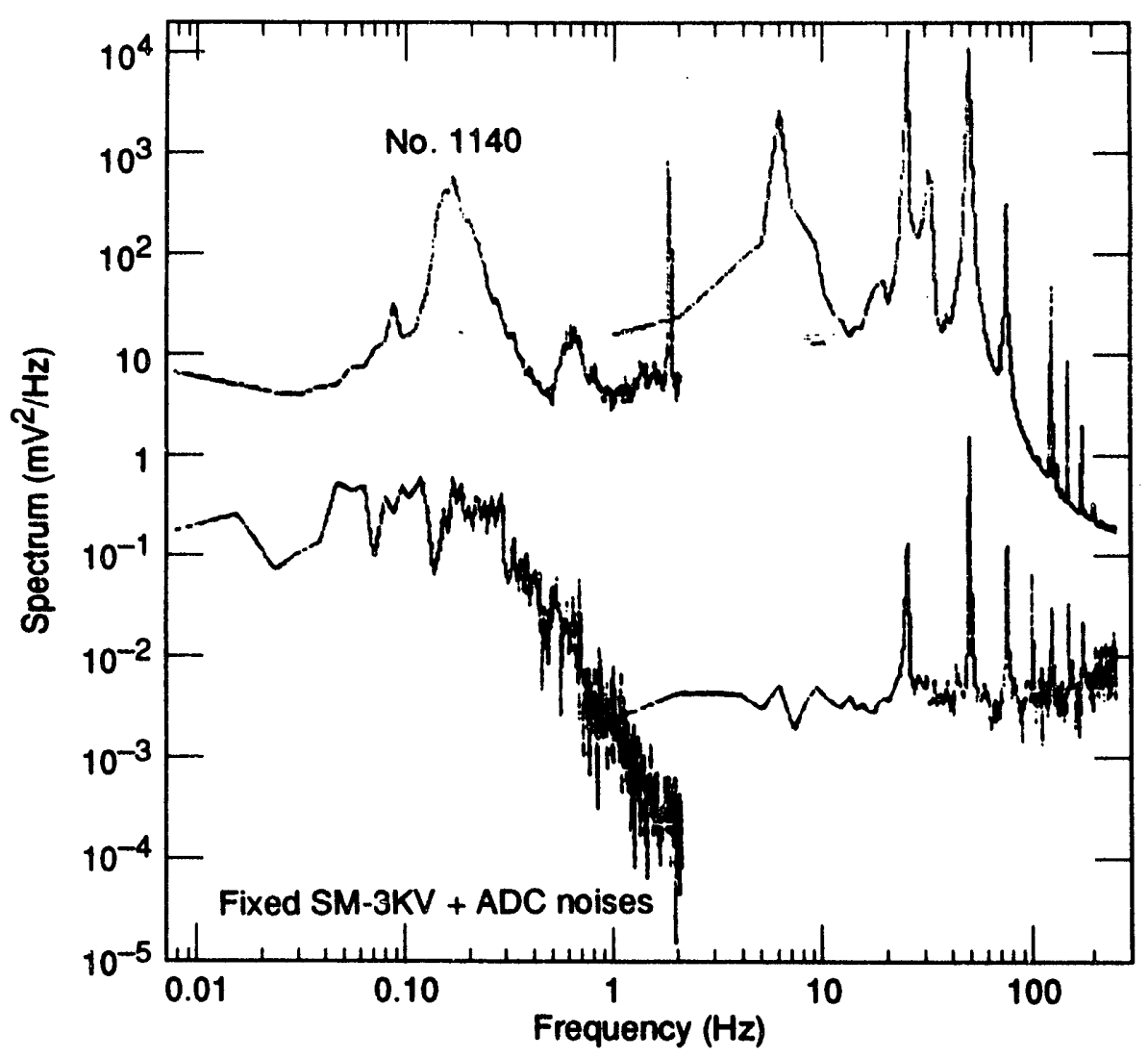

Flgure 2. Spectra of Noles and Slgnal from SM-3KV Probe.

The piezoceramic probes made by Dytran Corporation have sensitivity of approximately, $50 \mathrm{mV} /\left(\mathrm{m} / \mathrm{s}^{2}\right)$ in the frequency band of $20-4000 \mathrm{~Hz}(3 \mathrm{~dB}$ level). Each directional probe has a mass of approximately $100 \mathrm{~g}$ and is $2.5 \mathrm{~cm}$ in its largest dimension (height).

Signals from all probes were digitized and developed by a CAMAC-based experimental set-up named ASSA, which includes:

- CAMAC crate

- CAMAC crate controller

- Two 10-bit, 4-channel CAMAC ADC ZIIS-4 type

- CAMAC differential amplifiers for all kinds of probes (this allows us to change the total gain from 0.1 to $10^{5}$ and low-pass frequency filters from $1 \mathrm{~Hz}$ to $10000 \mathrm{~Hz}$ )

- Two 256-K, 24-bit word CAMAC memories

- CAMAC timer

- Interface CAMAC (IBM PC)

- IBM 386 personal computer.

The ASSA se'-up is fully autonomous and needs only a 110-V outtet.

Signals from all probes were digitized simultaneously by ADCs with a sampling frequency (changeable by timer up to $32 \mathrm{kHz}$ ) and then were sent to memory for storage. The maximum memory available for one channel is $64-\mathrm{K} 24$-bit words. It corresponds to $17.8 \mathrm{~h}$ of permanent measurement time with a sampling rate of $1 \mathrm{~Hz}$ or about $1 \mathrm{~min}$ with $1 \mathrm{kHz}$. For long measurements we used low-pass filters at $2 \mathrm{~Hz}$ or $20 \mathrm{~Hz}$; for fast analyses $2000-\mathrm{Hz}$ and $10000-\mathrm{Hz}$ band filters were applied. 
The software used allows us to analyze data in both the time and the frequency domain, to transform raw signal data to vibration amplitudes (i.e., transform volts to micrometers), to change all variable parameters of hardware (sampling frequency, gains, filters), to calculate spectra of power of all signals and spectra of correlation between all pair of channels, and to present results graphically and produce hard copy on a printer.

For calculations of spectra we used the optimized 512-point Raider-Brenner algorithm based on a 16point Winograd algorithm for discrete Fourier transformation. (See Reference 9 for an example.) On an IBM PC/386, the algorithm works twice as fast as the usual Fast Fourier Transformation (FFT) technique of Cooley and Tukey. This algorithm is very useful because in order to reduce statistical errors we can average over a greater number of spectra (usually 64). Two types of data filtration were used when necessary: Henning filter (see Reference 10 for an example), and the originally proposed Antimed filter (see Appendix), which provides more true data under some conditions.

The spectrum of correlation of two signals $X(t)$ and $Y(t)$ (or, mutual correlation spectrum) that we will use here is defined as:

$$
A(\omega)=\frac{\left\langle X(\omega) Y^{*}(\omega)\right\rangle}{\left[\left\langle|X(\omega)|^{2}\right\rangle\left\langle\left. Y(\omega)\right|^{2}\right\rangle\right]^{1 / 2}}
$$

Here the brackets <....> mean averaging over the 64 measurements, and $X(\omega)$ is the Fourier transformation of $X(t)$.

The main aims of our investigations were to determine:

1. Quantitative characteristics of the SSC sire ground vibration

2. Properties of the SSC superconducting dipole (warm condition)

3. Comparison and verification of data from both types (INP and SSCL) of high-frequency probes.

All results presented in Section 3.0 were obtained at the Accelerator System String Test (ASST) at the SSC Laboratory. An SSC superconducting dipole in warm condition and with open vacuum vessel (dipole cold mass was available) was used for the measurements. The single dipole was set on the ground without any special support system. Dytran probes connected to the dipole cold mass end were used, as were TA2 probes placed at different positions on the cold mass, on the vacuum vessel, and on the ground. SM$3 \mathrm{KV}$ geophones were installed, sometimes on the vacuum vessel and sometimes on the cold mass end. Usually one SM-3KV probe was placed on the ground near the dipole and another at $130 \mathrm{~m}$ along the ASST building. Under these conditions two SM-3KV probes were used to observe the correlation between the motion of two points situated about the SSC neighboring quadrupoles.

\subsection{RESULTS}

Figure 3 presents a comparison of vibrations on the cold mass and on the ground. Figures 3(a) and 3(b) show a sampling of high-frequency $(2 \mathrm{kHz})$ measurements at $0.512 \mathrm{~s}$; Figure 3(a) shows the signal of a SM-3KV on the end of the SSC dipole cold mass, and Figure 3(b) shows the signal from the floor near the dipole. The larger amplitude of the cold mass vibration is clearly seen. We should mention that the end of the cold mass was not connected with another dipole, as it will be in the collider string. Figures 3 (c) and 3(d) show that at lower frequencies the cold mass oscillations are similar to the measurement at the floor. Here the sampling frequency was $10 \mathrm{~Hz}$, at a full time of $72 \mathrm{~s}$, and a low-pass $(2 \mathrm{~Hz})$ filter was used. Thus, higher-frequency vibrations were strongly reduced. 

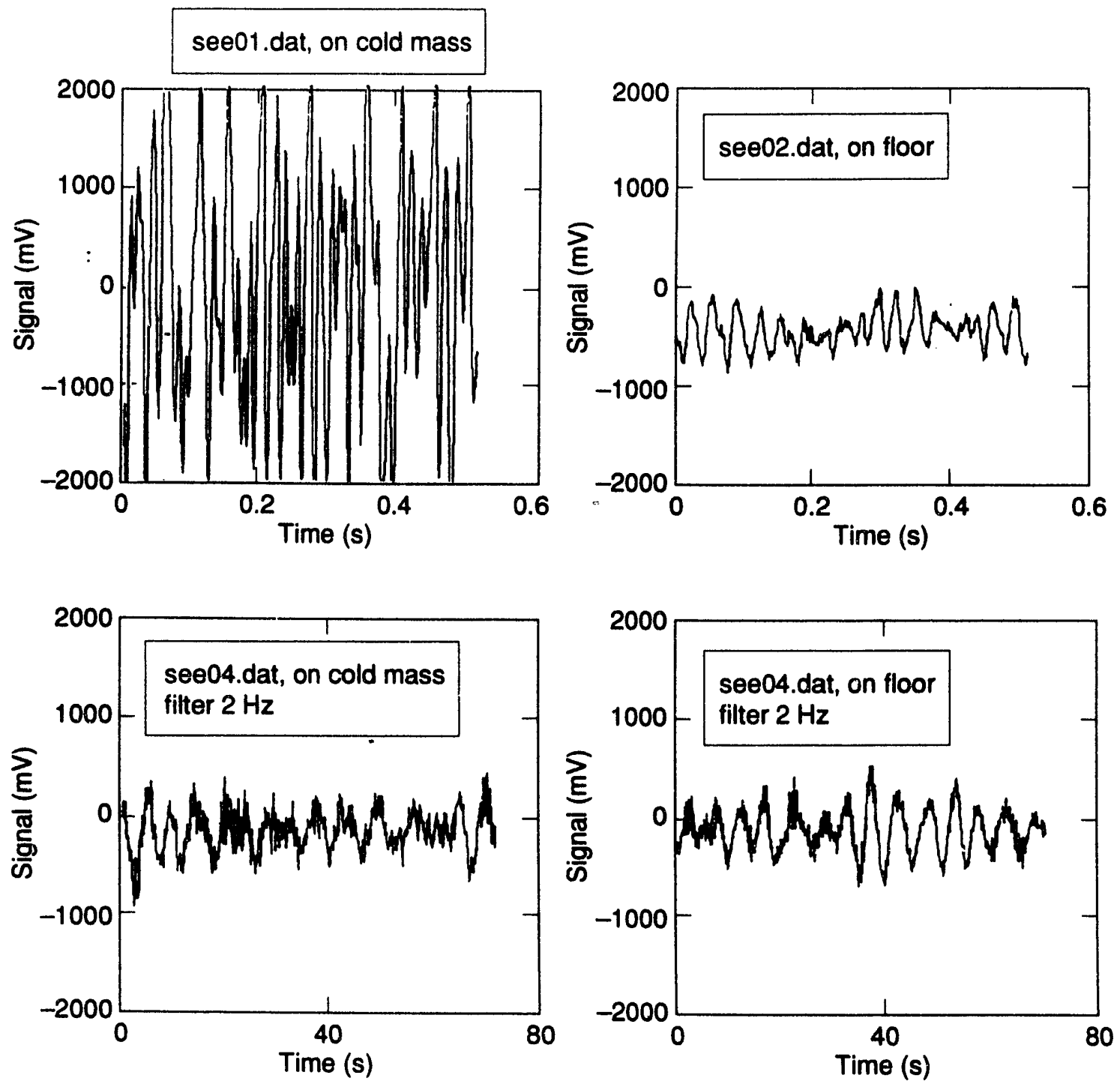

Figure 3. Vibrations of the SSC Dipole Cold Mases and the Ground. (Upper row, high-frequency data; lower row, low-irequency data.)

Spectral densities of the power of vibrations at the cold mass and on the floor in the frequency band 0.2-50 $\mathrm{Hz}$ are shown in Figure 4. One can see that at some frequencies connected with resonant properties of the dipole, the cold-mass vibrations are many times greater than on the floor. Note that the densities are presented in double logarithmic scale, and the probe calibration was taken into account. The dimension of the spectrum $S(f)$ is $\mu \mathrm{m}^{2} / \mathrm{Hz}$, which is common for irregular processes such as ground vibrations. To find an rms value of vibration in a frequency band, integrate the value of $S(f)$ over this band and take a square root of the obtained integral. For example, as shown in Figure 4 the value of $S(f)$ for floor vibration at frequencies of $10-50 \mathrm{~Hz}$ (full band $40 \mathrm{~Hz}$ ) is about $5 \times 10^{-8} \mu \mathrm{m}^{2} / \mathrm{Hz}$. Therefore the rms value of floor vibrations in this band is about $\left(5 \times 10^{-8} \times 40\right)^{1 / 2}=1.4 \times 10^{-3} \mu \mathrm{m}$. 


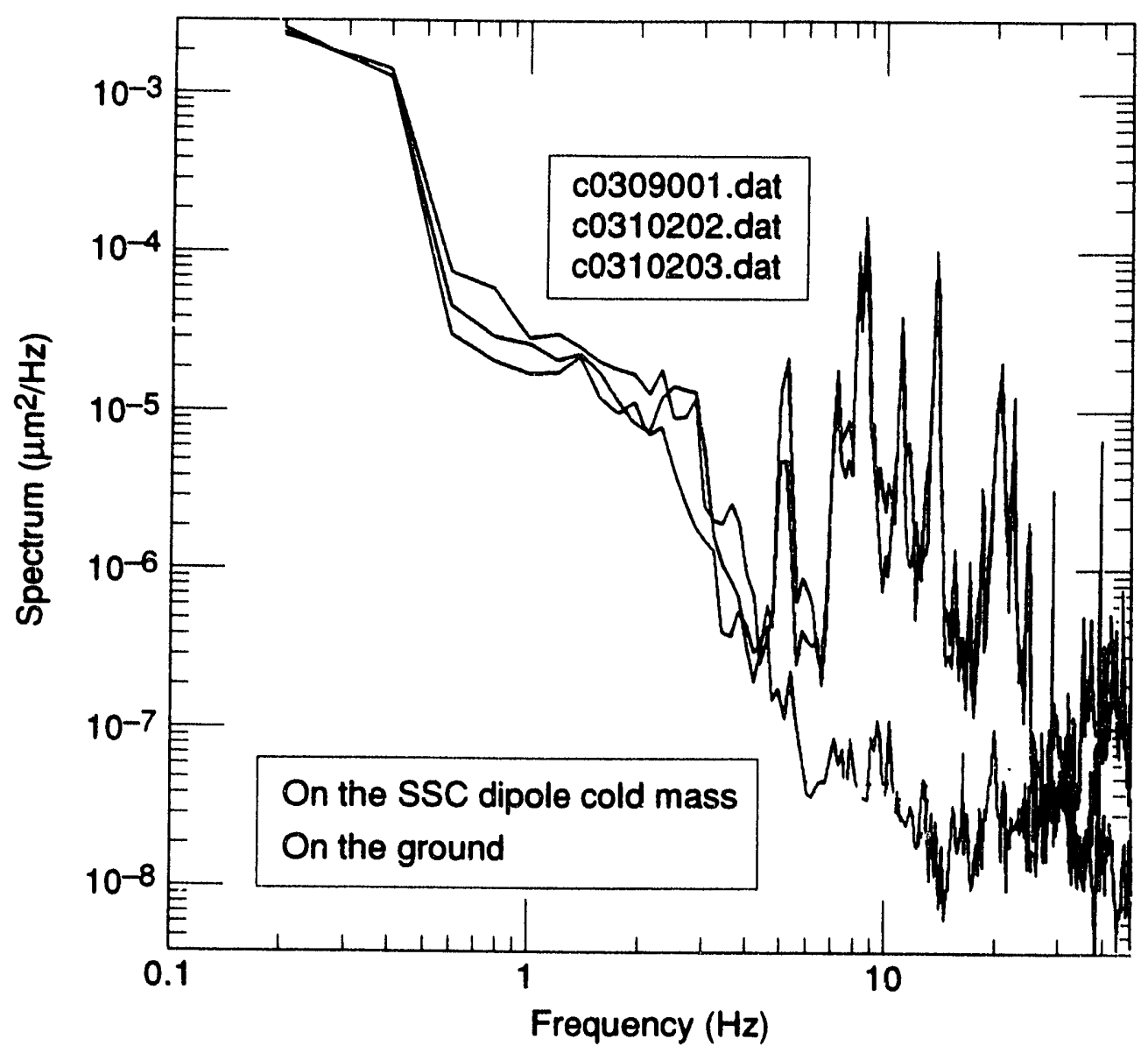

Figure 4. Spectral Denelty of Power of Vibratlons of the Cold Mase and the Ground. The probe callbration was taken Into account.

In Figure 5 the ratio of amplitudes of vibration (or amplitude transform ratio) on the cold mass and on the floor is presented. The amplitude transform ratio was calculated as the square root of the ratio of the corresponding spectra (see Figure 4). The picture consists of two parts: in the frequency band $0.2-50 \mathrm{~Hz}$, data measured by the SM-3KV type probe were used; in the band 7-1720 Hz, data by the TA2 probes were used. One can clearly see many resonances. Another way to observe the resonances is to note the dipole response after striking, which was made with Dytran equipment (see Figure 6). Coincidence of resonances found by both techniques is excellent at frequencies up to $75 \mathrm{~Hz}$. Additional resonances at $77 \mathrm{~Hz}, 80 \mathrm{~Hz}$, and $85 \mathrm{~Hz}$ exist in the striking technique result. This difference in measurements is due to differences in the ways of exciting the vibrations. Measurements made by SM$3 \mathrm{KV}$ and TA-2 probes in different places on the dipole indicate sometimes severe modes of the dipole cold mass and of the vacuum vessel (outer steel shield of the dipole). At higher frequencies it was hard to do that. Main resonances are described in Table 1. 


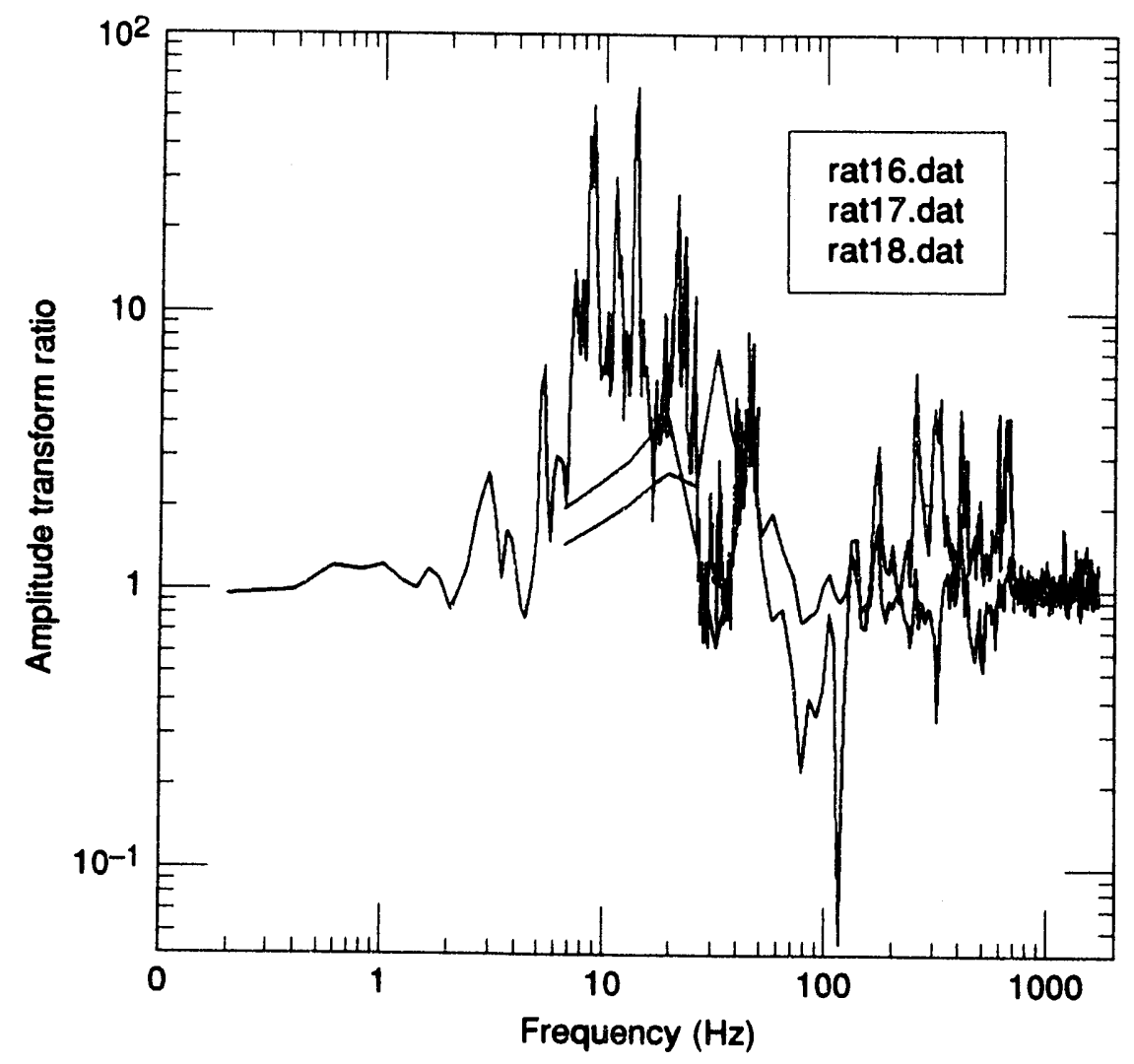

Flgure 5. Amplitude Transform Ratio for the Cold Mase of the SsC Dipols.

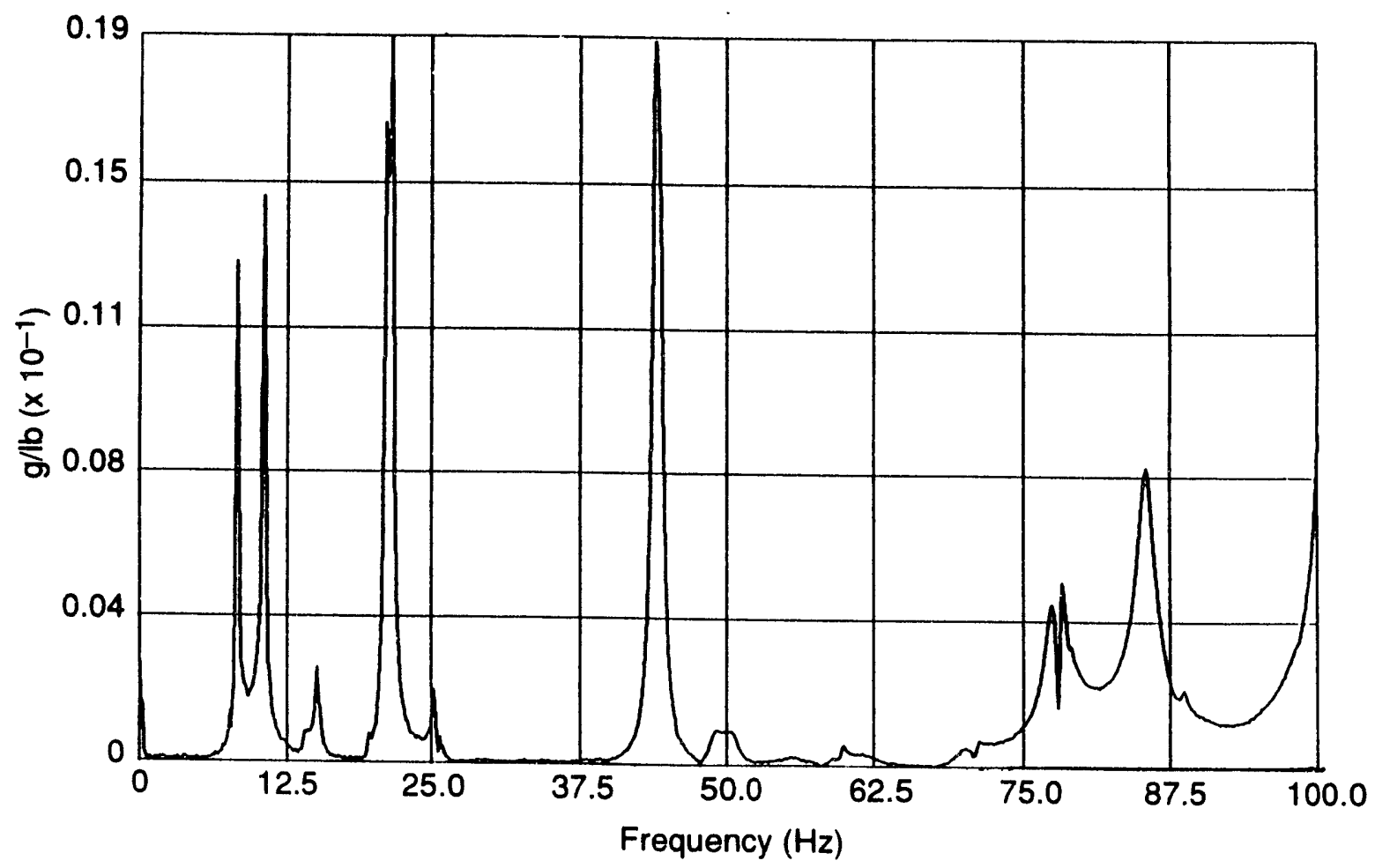

Flgure 6. Modal Analysis of the Dipolo-Striking Technique Data (Dipole 208). 
TABLE 1. RESONANCES.

\begin{tabular}{|c|l|}
\hline Main resonances of cold mase & \\
\hline $8.0 \mathrm{~Hz}$ & \\
$10.2 \mathrm{~Hz}$ & \\
$15.6 \mathrm{~Hz}$ & \\
$17.3 \mathrm{~Hz}$ & Amplitude ratio of cold mass \\
$20.3 \mathrm{~Hz}$ & to floor vibration is in the range of 10-100. \\
$22.5 \mathrm{~Hz}$ & \\
\hline $25.3 \mathrm{~Hz}$ & \\
\hline Main resenances of vacuum vesed & \\
\hline $4.7 \mathrm{~Hz}$ & Amplitude ratio of cold mase \\
$12.3 \mathrm{~Hz}$ & to floor vibration is in the range of 3-70. \\
$30.2 \mathrm{~Hz}$ & \\
$17.3 \mathrm{~Hz}$ & \\
$35.9 \mathrm{~Hz}$ & \\
\hline Complex resonances & \\
\hline $45.7 \mathrm{~Hz}$ & \\
$84.6 \mathrm{~Hz}$ & \\
$247.4 \mathrm{~Hz}$ & \\
$440 \mathrm{~Hz}$ & Amplitude ratio of cold mass \\
$540 \mathrm{~Hz}$ & to floor vibration is in the range of 2.5-10. \\
$917 \mathrm{~Hz}$ & \\
$963 \mathrm{~Hz}$ & \\
$1373 \mathrm{~Hz}$ & \\
$1470 \mathrm{~Hz}$ & \\
\hline
\end{tabular}

Figure 7 shows the spectral density of the power of vibrations in the very broad frequency band (available from equipment) of $0.07-1720 \mathrm{~Hz}$ in double logarithmic scale. This spectrum consists of three parts:
$0.07-2.0 \mathrm{~Hz}$
ground motion measured by SM3-KV
(sampling frequency $4 \mathrm{~Hz}, 2-\mathrm{Hz}$ filter);
$0.2-50 \mathrm{~Hz}$
vibration of the cold mass and the floor measured by SM3-KV (100-Hz sampling);
$7-1720 \mathrm{~Hz}$
vibration of the cold mass and the floor measured by TA-2 (3440-Hz sampling). 


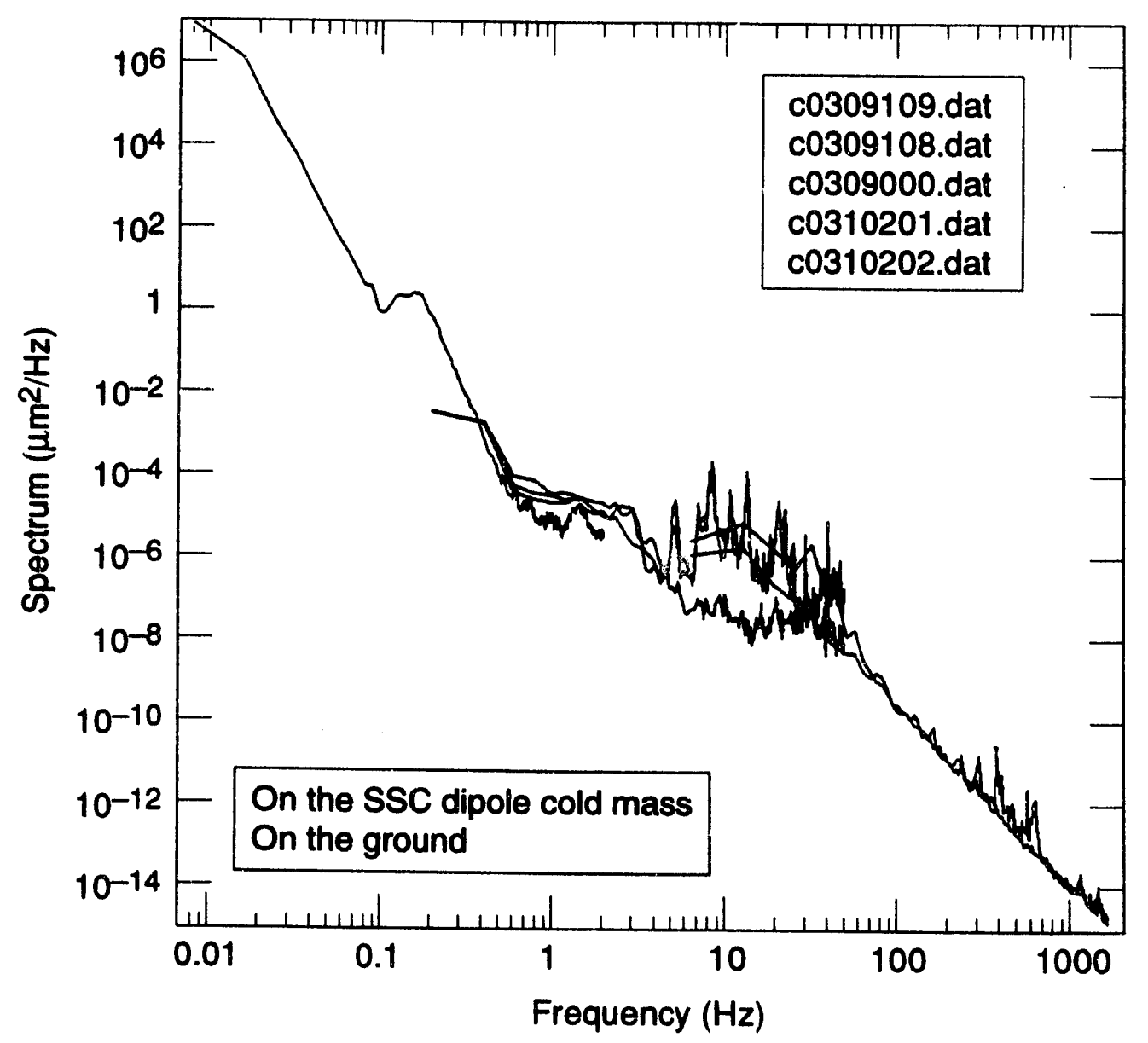

Figure 7. Spectral Denelty of Power of Vibrations in Very Broad Frequency Band (Avaliable from Equipment) of 0.07-1720 Hz.

Some interesting features are clearly seen: (1) an increase of the vibration power at low frequencies; (2) microseismic peak at $0.1-0.2 \mathrm{~Hz}$; and (3) an increase in mechanical resonances (described above).

The origin of the microseismic peak (the "7-second hum," so-called in spite of the fact that the mean frequency of the peak can vary from $0.07 \mathrm{~Hz}$ to $0.25 \mathrm{~Hz}$ and may consist of few peaks 7 ) is usually connected with ocean waves in the closest sea area. (The amplitude of the waves depends on time.) For example, in Figure 8 a 3-week observation of low-frequency motion is presented. One can see that the rms value of ground vibrations in the band $0.1-1 \mathrm{~Hz}$ (around the microseismic peak) varies by an order of magnitude. The behavior of this value was well correlated with weather conditions in Florida and over the ocean (it rises during storms). Sharp peaks of 1-2 $\mu \mathrm{m}$ are connected with small earthquakes. During these earthquakes the amplitudes of motion at a frequency of approximtately $0.05 \mathrm{~Hz}$ were $0.1-0.3 \mathrm{~mm}$ $(100-300 \mu \mathrm{m})$. Each of these quakes existed for approximately $1 \mathrm{~h}$. 


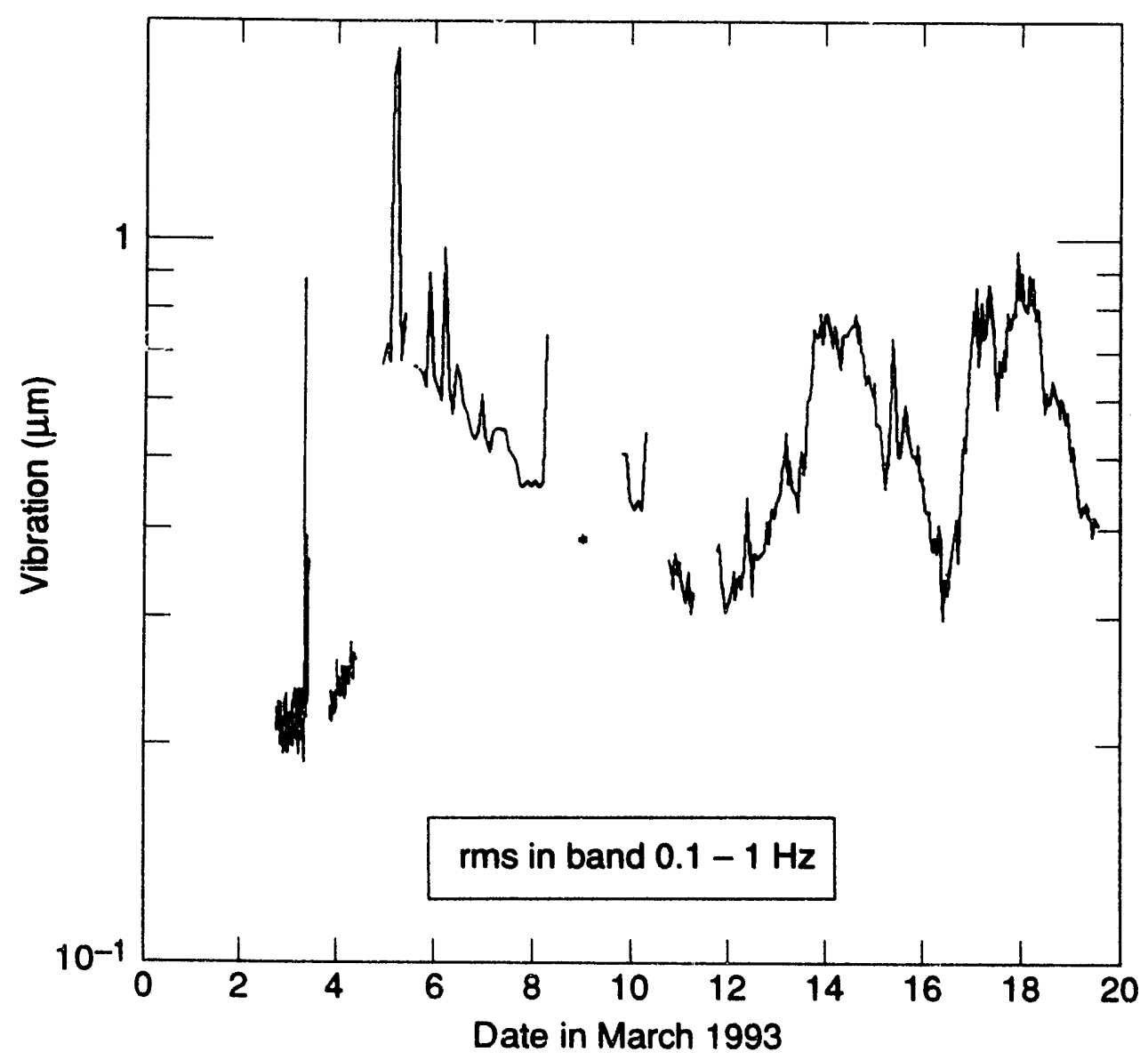

Figure 8. Three-Week Observation of Low-Frequency Ground Motion.

Figure 9 presents a real part (solid curve) and an imaginary part (dashed) of spectrum of the correlation between two SM-3KV probes distanced at $130 \mathrm{~m}$ (i.e., placed at two different ends of the ASST building) in logarithmic scale of frequency. The spectra show the degree of correlation between the same Fourier harmonics of two different signals. The value of 1.0 means full correlation; - 1.0, full anti-correlation; 0.0 , absence of correlation. The figure shows that the vibration of two distanced points is fully correlated at the frequency of microseismic peak, and a correlation of approximately 0.5 exists at frequencies of approximately $1-2 \mathrm{~Hz}$. No other significant correlations were observed.

The time dependence of the value of $\phi=\arctan (\operatorname{Im} K(\omega) / \operatorname{Re} K(\omega))$, which is connected with the direction of microseismic wave propagation, is shown in Figure 10 . A $90^{\circ}$ angle corresponds to the South-North direction. If the wave's source moves or changes place, then the angle changes. In the SSC site measurements shown in Figure 10, the maximum angle variation during March 1993 was about 30 .

A 3-week observation of vibrations of the floor at the ASST at frequencies above $1.0 \mathrm{~Hz}$ shows that vibrations at higher frequencies also vary by an order of magnitude (see Figure 11) and depend mostly on cultural excitation in the building and its surroundings (compressors, boring machines, cars, etc.). The lowest levels usually were observed at night. 


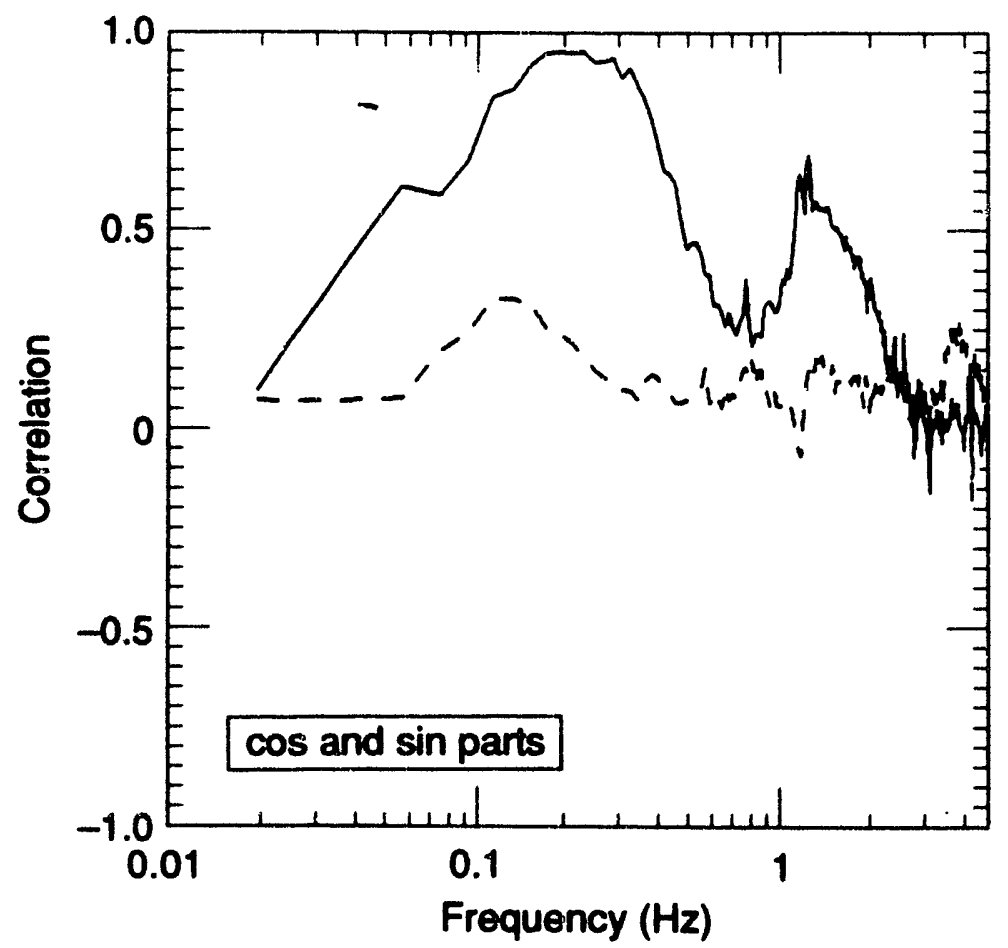

Figure 9. Spactre of Correlation of Ground Motion at $130 \mathrm{~m}$ Dibtanco.

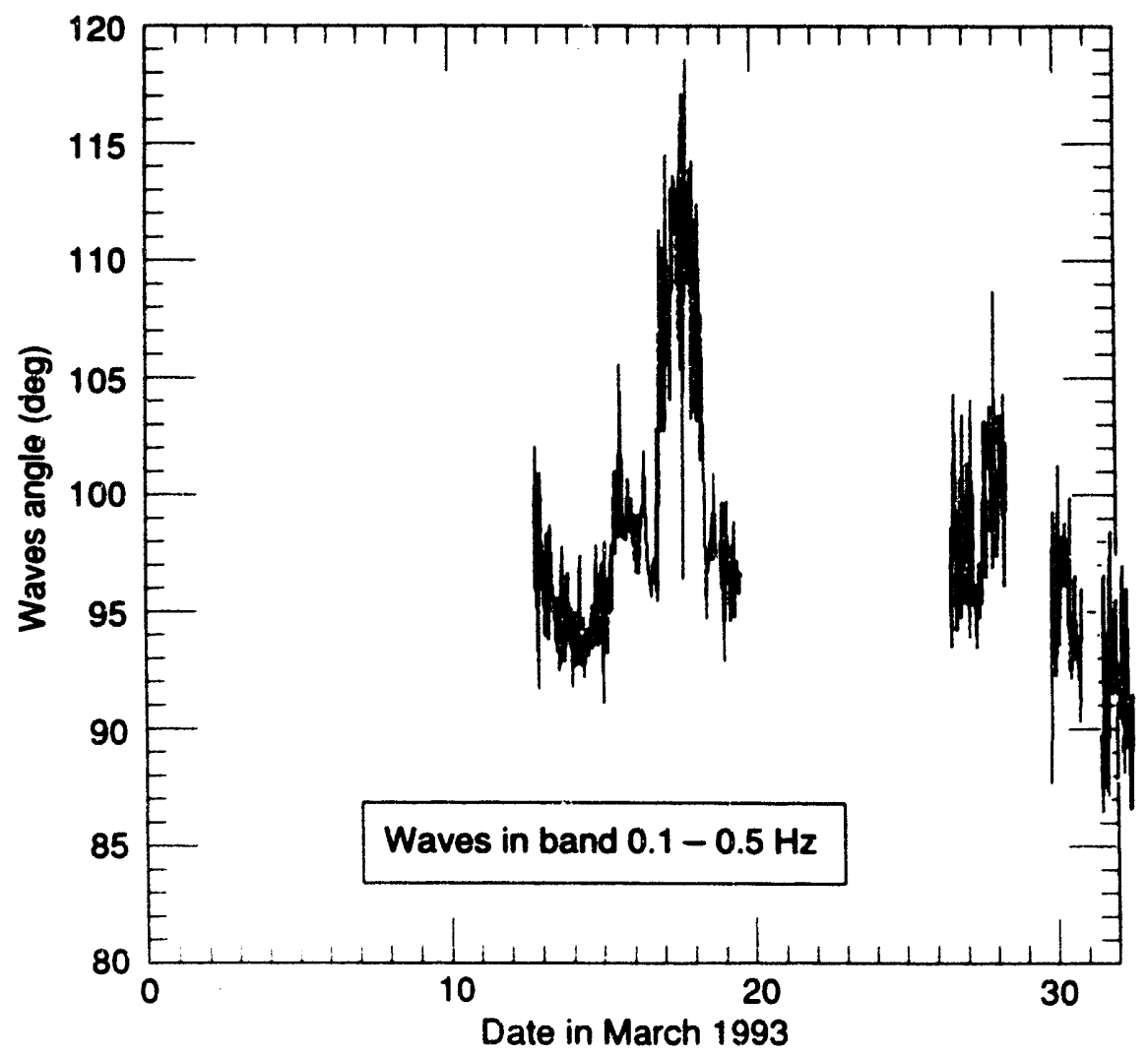

Figure 10. Direction of Propagation of Microselemic Waves; 90 Corresponds to South-North. 


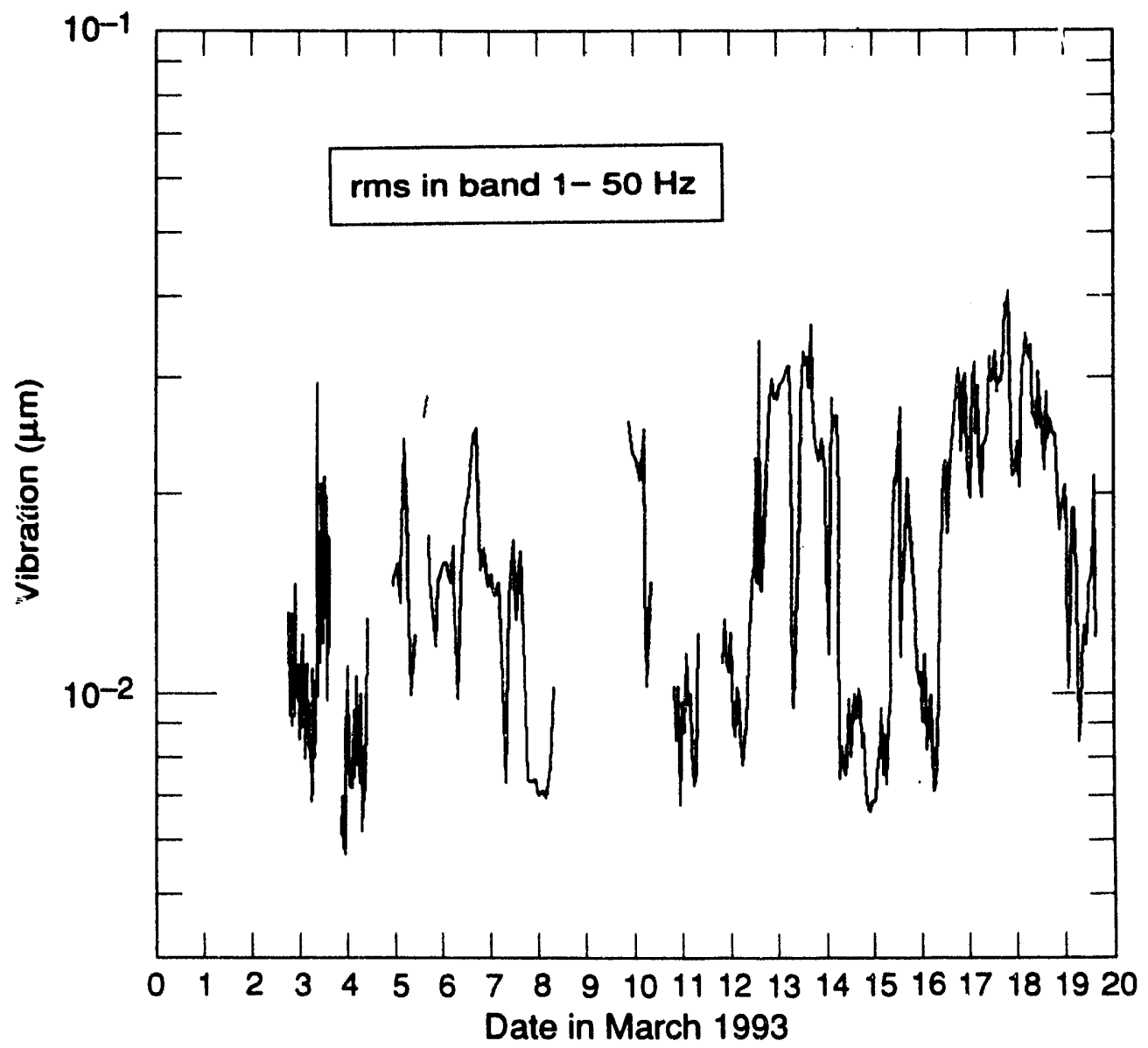

Flgure 11. Three-Weak Observation of Vibrations of the Floor at ASST at Frequencles above $1.0 \mathrm{~Hz}$.

Proper noises of the Dytran probe ( $1 / f$ noise spectrum below $1 \mathrm{kHz}$ and $1 / f^{2}$ in the band $1-4 \mathrm{kHz}$ ) were from 100 to 20 times greater in power than ambient ground motion noise. The most probable sources of noise are the field transistor mounted inside the probe and the piezoelectric element. We designed and tested a special resonant vibration plate-amplifier (similar to a musical tuning fork) for the Dytran probe.

Figure 12 shows the spectra of signals from the TA-2 probe and the Dytran probe with the resonant plate, both mounted on the dipole cold mass. The gain in the TA-2 channel is 1000; the gain in the Dytran channel is 10000 . The sensitivity of TA-2 is 5.0 V/G; of Dytran, 0.5 V/G (G = acceleration of gravity). Therefore the spectra must be the same. Resonant peaks connected with the plate are clearly seen at frequencies of $550 \mathrm{~Hz}, 1040 \mathrm{~Hz}, 1640 \mathrm{~Hz}, 1880 \mathrm{~Hz}, 2200 \mathrm{~Hz}$, and $4820 \mathrm{~Hz}$. Because of the impossibility of using TA-2 probes at liquid helium temperatures, only Dytran probes with amplifying plates could be used at the next ASST cold-run measurements. 


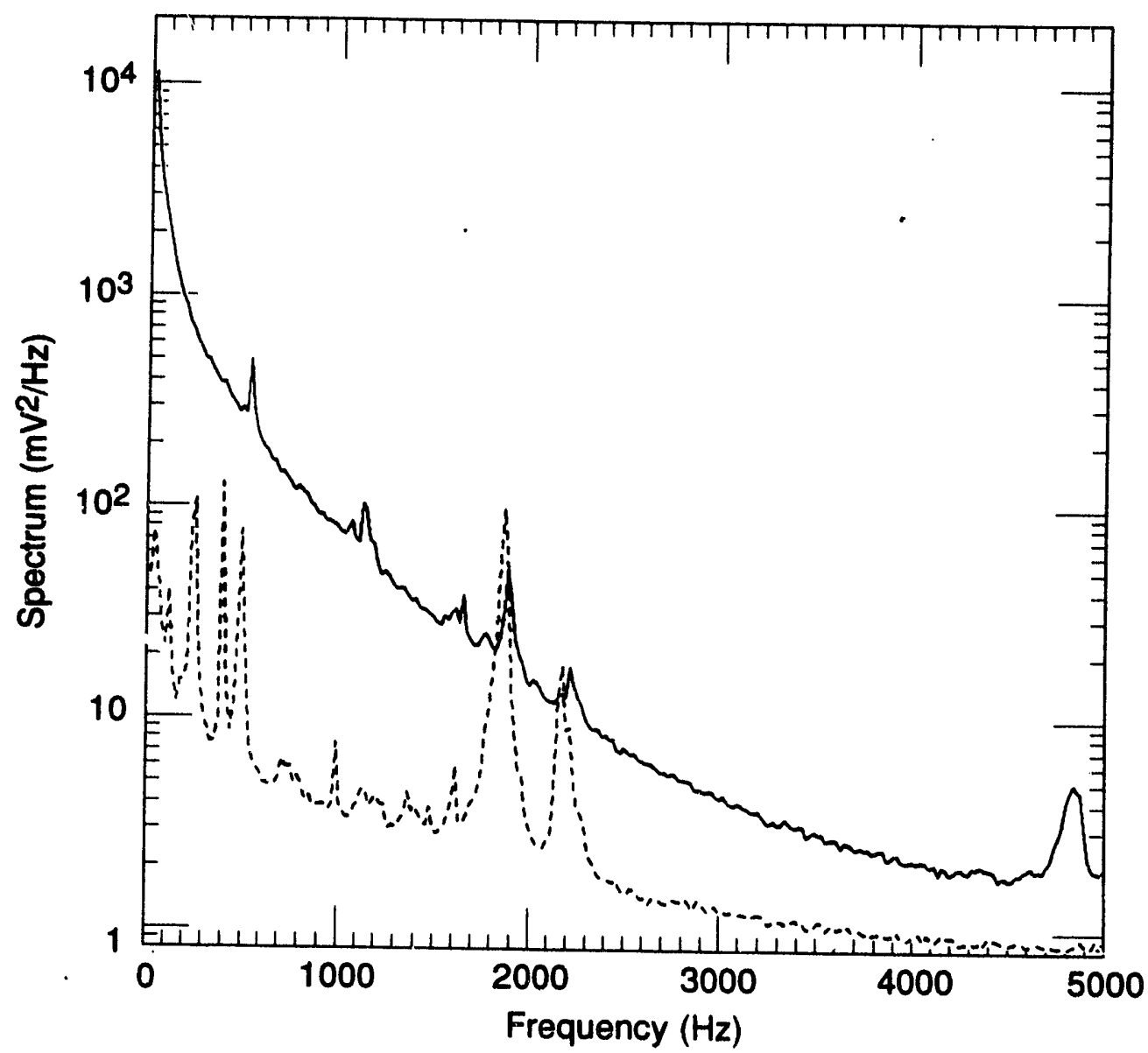
Figure 12. Spactre of elgnals from TA-2 Probs (Lower) and Dytran Probe with Reconant Plate (Upper),
Both Wounted on the Dipole Cold Mase.

Comparison of the measured ground motion spectrum with other data1,7,8,11 is presented in Figure 13. One can see that the SSC site is not the noisiest one. The differences of all data at frequencies of 10-200 Hz are mostly due to different cultural noise "vibroclimates." As we pointed out earlier, the microseismic peak depends on the distance to the nearest oceans and the weather activity above them. At frequencies below $0.05 \mathrm{~Hz}$ divergence is not well understood, and more careful measurements with superlow-frequency seismoprobes (for example, the SDE type ${ }^{12}$ ) are necessary because of the interest from the point of view of slow closed-orbit distortions in the SSC.

Finally, Figure 14 shows a comparison of the quietest and the largest spectra of ground vibrations with closed orbit distortions (COD) and emittance growth limitations as listed in Section 1.0. One can see that the measured high-frequency vibration level lies on the border of acceptability. At frequencies of approximately $0.1 \mathrm{~Hz}$ and below the level of ground motion is significantly high, but there is no full information about the space correlation of such motion. Some experimental data show significant uncorrelated motion of different points of the ground, even for very slow processes. ${ }^{13}$ 


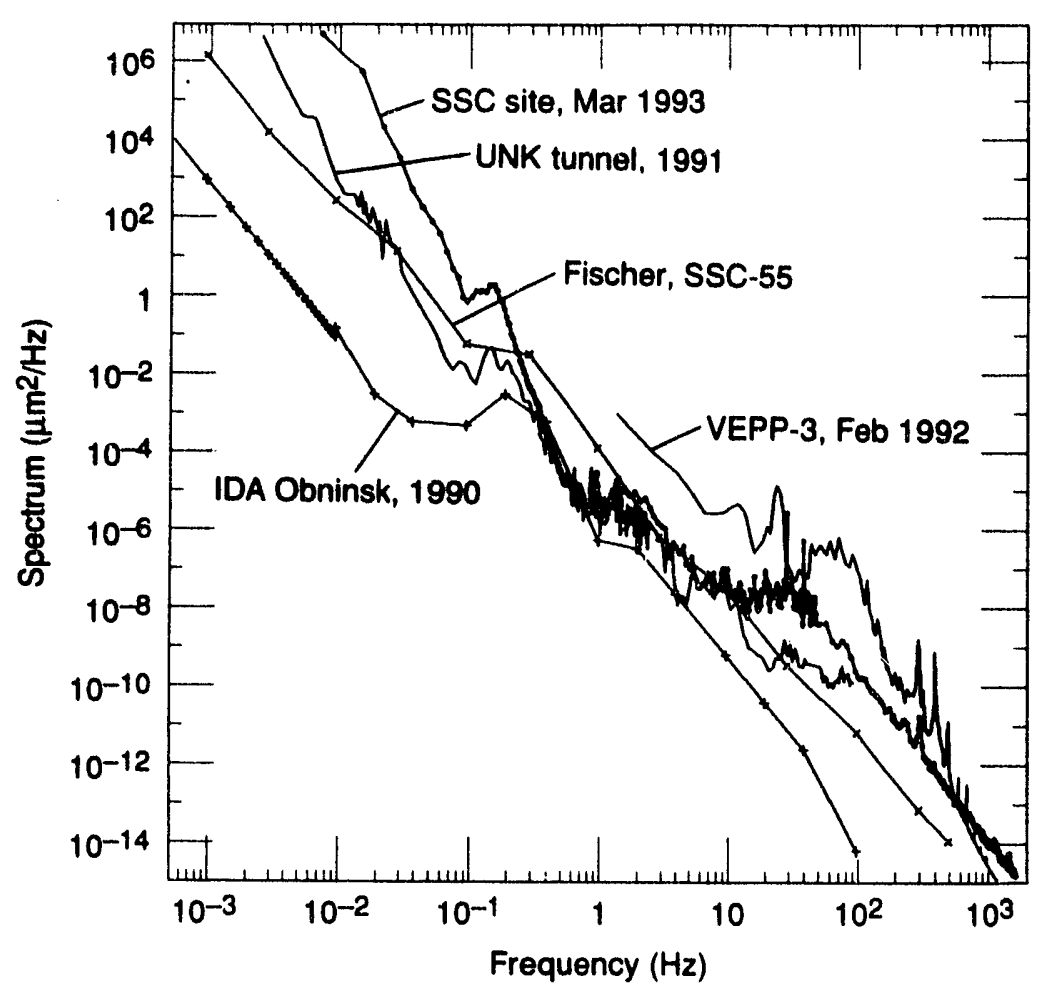

Figure 13. Comparicon of the ssC sho-Measured Spectrum of the Cround Motion wtth Other Data.

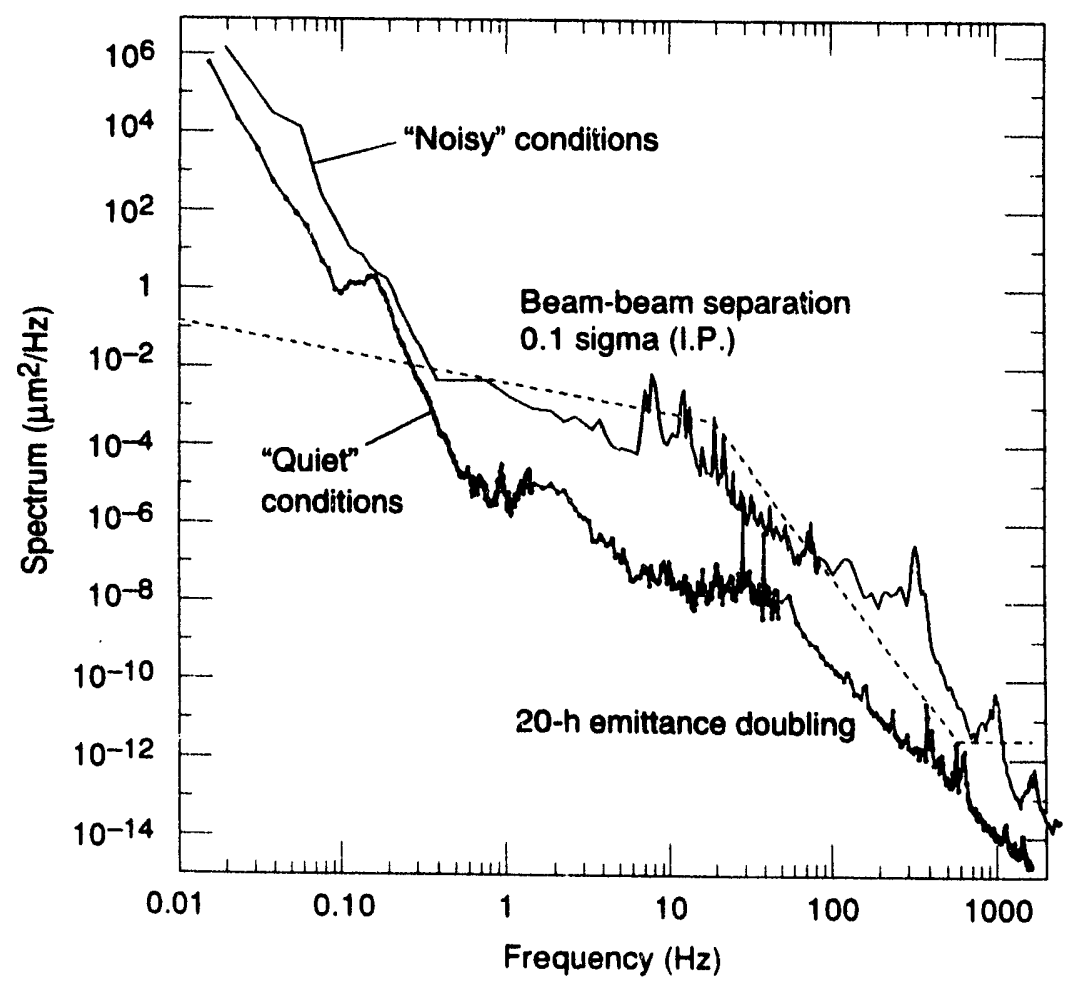

Figure 14. Measured Spectra of the Ground Motion In Nolsy and in Qulet Conditions in Comparison with Lovel of Accoptability. 


\subsection{ESTIMATION OF BEAM MOTION}

Let us consider the motion of ground with some frequency $\omega$. The displacement of the point of the ground with coordinate $r$ at the time $t$ can be written in the form:

$$
\Delta z(r, t)=A \exp (i k r-i \omega x)+f(r) \exp (-i \omega x) .
$$

The first term in the sum describes regular wave motion from a remote source, which is common for all points in the region in which we are interested. The second term is connected with numerous local sources and has a finite-correlation radius $\rho$ :

$$
\begin{array}{rlrl}
<f(r 1) f(r 2)> & =f^{2} & & \text { if }|r 1-r 2|<\rho \\
& =0 & \text { if }|r 1-r 2|>\rho
\end{array}
$$

Correlation of motion for two points at $r 1$ and $r 2$ distanced more than $\rho$ is equal to:

$$
\text { Corr }=\frac{\langle\Delta z(r 1) \Delta z(r 2)\rangle}{\left\langle\Delta z^{2}\right\rangle}=\frac{A^{2}(\operatorname{Cos} \phi+i \operatorname{Sin} \phi)}{\left(A^{2}+f^{2}\right)},
$$

where $\phi=k(r 1-r 2)$.

For calculation of COD $X$, one should summarize all kicks produced by quadrupole displacements around the collider ring:

$$
\begin{gathered}
X=\frac{\beta^{1 / 2} * \text { Sum }}{(2 \pi \sin (\pi v))}, \\
\operatorname{Sum}=\frac{\sum \beta_{i}^{1 / 2} \Delta_{\mathrm{z}_{i} \cos \left(\theta-\theta_{i}-\pi v\right)}}{F_{i}} .
\end{gathered}
$$

Here $\beta, \theta$, and $v$ are beta-function, betatron phase, and tune, respectively, and $F_{i}$ is the focal length of the $i$-th quadrupole. The largest values of closed orbit distortions will occur when ground waves propagate in resonance with betatron beam oscillations. Simple analysis shows that the minimal frequency, $F_{m}$, acceptable for this condition is approximately

$$
F_{m}=V W P,
$$

where $V$ is the velocity of ground wave and $P$ is the circumference of the ring. At the SSC, $P=89000 \mathrm{~m}$, $V=2100 \mathrm{~m} / \mathrm{s}$ in Austin chalk at the depth of the ring, and $v=123.7$; thus $F_{m}=2.6 \mathrm{~Hz}$.

However, results of measurements show that at frequencies above 1-2 $\mathrm{Hz}$, movements of two points distanced at $100 \mathrm{~m}$ are practically non-correlated. So, in our estimates we have neglected regular wave motion at these frequencies.

For irregular ground motion one can take into account the random character of motion of different quadrupoles. The calculation of COD, assuming that the main part of the ring is a FODO lattice with phase advance per cell $\mu$ and the full number of quadrupoles is $N$, gives the following result: ${ }^{3}$

$$
X^{2}=\frac{\beta \tan (\mu / 2) N\left\langle f^{2}\right\rangle}{4 l \sin ^{2}(\pi v)},
$$


and, according to previous considerations:

$$
\left\langle f^{2}\right\rangle=\left\langle\Delta_{z i}{ }^{2}\right\rangle(1-\mid \text { Corr } \mid)
$$

Here $\beta$ is the value of the beta function at the observation point of the ring, and $l$ is the stance between neighboring lenses. In our estimations we took $N=1000, \beta=\langle\beta\rangle=120 \mathrm{~m}$, and $l=9 \gamma_{1}$.. Values of $\Delta z^{2}$ at each frequency were taken from the measured spectra file similar to those presented in Figures 7 and 9. Analogously, values of correlation were taken from the measured correlation file. Using the last two formulas we estimated the spectrum of COD. Figure 15 shows the result of integrations over those spectra from the given frequency $F$ and above, for frequencies $F$ from $0.02 \mathrm{~Hz}$ to $1720 \mathrm{~Hz}$.

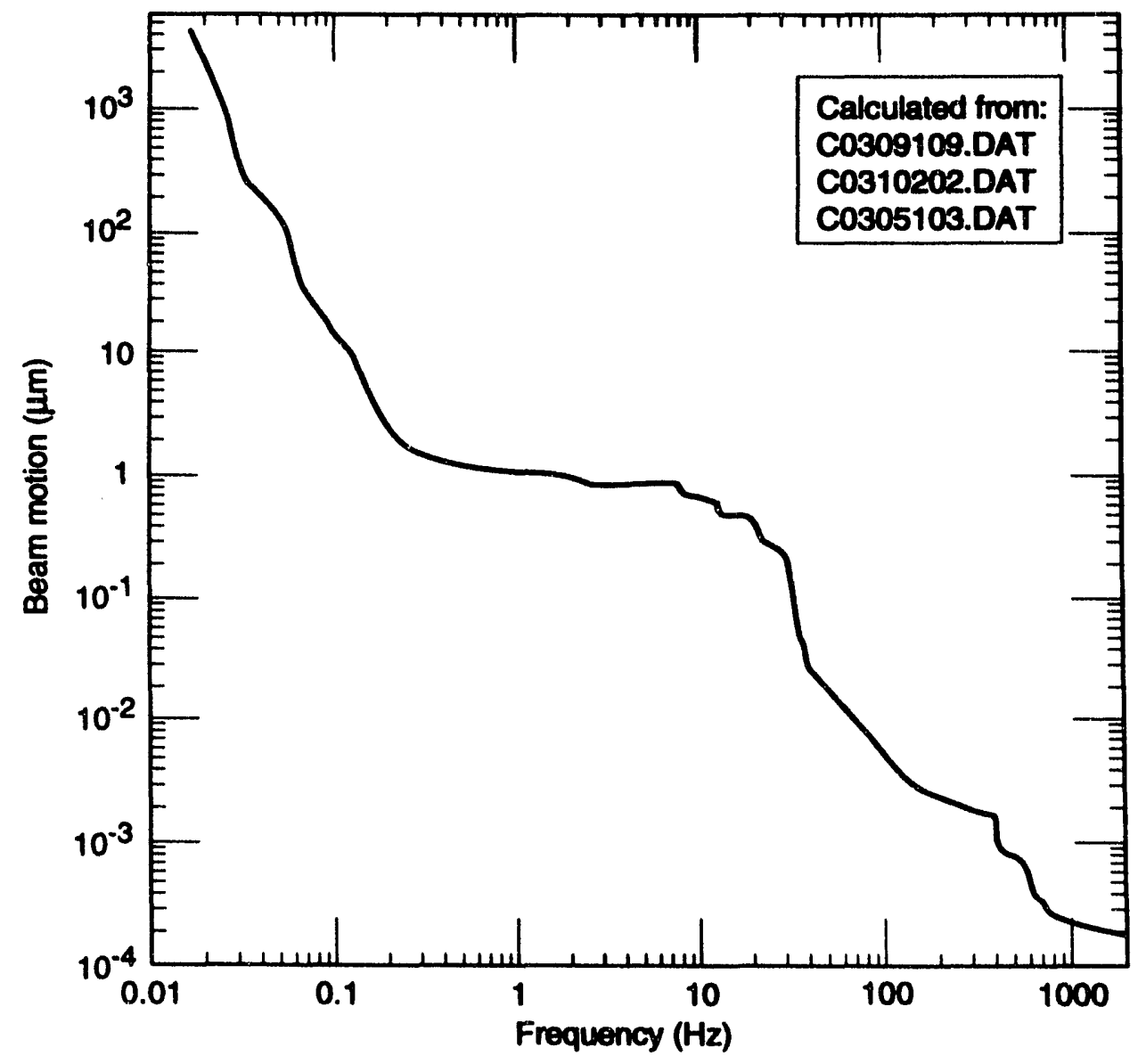

Figure 15. Calculated Motion of the SsC Beam ve. Frequeney, Due to Ground Motion.

\subsection{SUMMARY AND FURTHER DEVELOPMENT OF EXPERIMENTS}

Seismic ground measurements at the SSC site (ASST building) and investigations of vibrational properties of superconducting dipoles for the SSC were carried out during March 1993. The equipment used allowed us to obtain data in the very large frequency band of $0.05-2000 \mathrm{~Hz}$.

We found that at high frequencies above $10 \mathrm{~Hz}$, the main source of vibration is human activity. Analysis shows that in very quiet conditions, ground motion vibrations at high frequency are not 
dangerous for the SSC transverse emittance growth. Nevertheless, the motion of the magnetic elements associated with operation of laboratory compressors, power supplies, etc., and of other man-made activity-even without liquid helium flow in the magnets (predicted as the main source of beam vibrations) -is unacceptably large and will cause fast emittance decay. We think that the most reasonable way to prevent influence of such motion on the SSC beam is to use a transverse beam-based feedback system, in spite of attempts to improve the mechanical properties of the magnets.

At frequencies below $0.3 \mathrm{~Hz}$ the amplitudes of magnets and the ground motion are the same. These vibrations are very powerful at the SSC site (in comparison with other places) and have a natural origin (ocean waves). They will lead to beam-beam separation in the interaction point, which should be corrected by a slow adjustment system ("Jostlein scheme,"14 for example).

During 6 weeks of measurements, three significant earthquakes occurred (one on the Northwest coast of the United States, one near San Antonio, TX, and the last at an unidentified site). The characteristic amplitude of earthquake vibrations is $\mathbf{3 0} \mu \mathrm{m}$ and more; the characteristic frequency is approximately $0.05 \mathrm{~Hz}$ (20-s period) or lower; and the usual time of such a "seismic storm" is a few hours. For a better understanding of the influence of such low-frequency motion on SSC operations, measurements of amplitude and space correlation properties are necessary.

Our future plans include:

1. Measurements of the SSC dipole vibrations with prepared Dytran, TA-2, and SM-3KV probes during the next "cold" ASST run (Summer 1993).

2. Measurements of SSC tunnel ground motion.

3. Super-low-frequency measurements at the SSC site.

\section{ACKNOWLEDGMENT}

The authors are grateful to Mike Henges for his help in the preparation of measurements.

We also wish to thank Dr. J. O. Peterson for reading and commenting on the manuscript. 


\section{REFERENCES}

1. G. E. Fischer and P. Morton, "Ground Motion Tolerances for the SSC," SSC-55, 1986.

2. K. Y. Ng and J. O. Petersen, "Ground Motion Effects on the SSC," SSC-212, 1989.

3. V. A. Lebedev, V. V. Parkhomchuk, V. D. Shiltsev, and A. N. Skrinsky, "Suppression of Emittance Growth Caused by Mechanical Vibrations of Magnetic Elements in Presence of BeamBeam Effects in the SSC," Preprint LVP 91-120, Novosibirsk, 1991.

4. V. A. Lebedev, V. V. Parkhomchuk, Y'. D. Shiltsev, and G. V. Stupakov, "Emittance Growth Due to Noise and Its Suppression with th: Feedback System in Large Hadron Colliders," SSCLPreprint-188, 1993.

5. The Earth Technology Corporation (Long Beach, CA), "Field Measurements and Analyses of Underground Vibrations at the SSC Site," Report No. SSC-SR-1043, Dec. 1989.

6. "Summary and Presentations of the Workshop on Vibrational Control and Dynamic Alignment Issues at the SSC," ed. H. J. Weaver, SSCL-SR-1185, Feb. 1992.

7. B. A. Baklakov, P. K. Lebedev, V. V. Parkhomchuk, A. A. Sery, V. D. Shiltsev, and A. I. Sleptsov, "Investigation of Seisrinic Vibrations and Relative Displacement of Linear Collider VLEPP Elements," Proc. of 1991 IEEE Part. Aicel. Conf., San Francisco, p. 3273, May 1991.

8. V. A. Lebedev, P. K. Lebedev, V. V. Parkhomchuk, and V. D. Shiltsev, "Transverse Vibration of Electron Beam and Ground Motion Measurements at VEPP-3 Storage Ring," Preprint INP 92-39, Novosibirsk, 1992.

9. R. E. Bleihut, Fast Algorithms of Data Processing, Addison-Wesley, 1985.

10. R. W. Hamming, Digital Filters, Prentice-Hall, Englewood Cliffs, N.J., 1977.

11. H. K. Given, "Variations in Broadband Seismic Noise at IRIS/IDA Stations in the USSR with the Implementations for Event Detection," Bulletin of the Seismological Society of America, Vol. 80, No. 6, p. 2072, Dec. 1990.

12. V. A. Lebedev and P. K. Lebedev, private communication.

13. V. V. Parkhomchuk and V. D. Shiltsev, "Fractal Model of tine Ground," INP Preprint 92-31, Novosibirsk, 1992 (in Russian).

14. H. Jostlein, "Automatic Beam Centering at the SSC Interaction Regions," Fermilab TM-1253, March 1984. 


\section{APPENDIX \\ “ANTIMED” DIGITAL FILTER}

The originally proposed non-linear filter "Antimed" allows us to fully prevent the phenomenon-wellknown in digital filtration theory-of "leaking" of energy. The filter is useful when it is necessary to investigate properties of small signals and noises in the presence of large, regular (periodic) signals. The Antimed filter in this case gives true results for ail Fourier components of the signal.

The algorithm of the Antimed filter is very simple:

1. Make a Discrete Fourier Transformation (DFT) of input data array $X\left(t_{\mathfrak{i}}\right)$.

2. Apply antimedian transformation to each Fourier amplitude $X\left(f_{i}\right)$

[to both real $\operatorname{Re}_{\mathrm{i}}=\operatorname{Re}\left(X\left(f_{\mathrm{i}}\right)\right)$ and imaginary $\operatorname{Im}_{\mathrm{i}}=\operatorname{Im}\left(X\left(f_{\mathrm{i}}\right)\right)$ parts] according to the algorithm:

$$
\begin{aligned}
& \operatorname{Re}_{i}^{\text {new }}=\operatorname{Re}_{i}-\text { mediana }\left(\operatorname{Re}_{i-1}, \operatorname{Re}_{i}, \operatorname{Re}_{i+1}\right) \\
& \operatorname{Im}_{i}^{\text {new }}=\operatorname{Im}_{i}-\text { mediana }\left(\operatorname{Im}_{i-1}, \operatorname{Im}_{i}, \operatorname{Im}_{i+1}\right),
\end{aligned}
$$

where mediana $(x, y, z)$ is equal to $x$ or $y$ or $z$, depending on which is closest to the value of $(x+y+z) / 3$. For example,

$$
\begin{aligned}
& \text { mediana }(1,0,2)=1 \\
& \text { mediana }(-5,100,13)=13 \\
& \text { mediana }(33,34,35)=34
\end{aligned}
$$

3. Multiply new values of $X\left(f_{i}\right)$ by the weight factor $(4 / 3)^{1 / 2}$.

Figure A.1 shows the effect of the application of different digital filters to the data, which are equal to sine function with the addition of white noise of 100 times less amplitude. In Figure A.1, (a) shows the real, (i.e., continuous) Fourier spectral power of density of the signal; (b) shows the DFT of the data without any filter; (c) is the DFT with Henning filter; ${ }^{10}$ (d) is the DFT with Antimed filter.

One can see that Antimed filter gives a result closer to the real one. We used this filter at low sampling frequencies when the microseismic peak signal artificially increases (after digitizing) the levels of correlation at frequencies below it. 


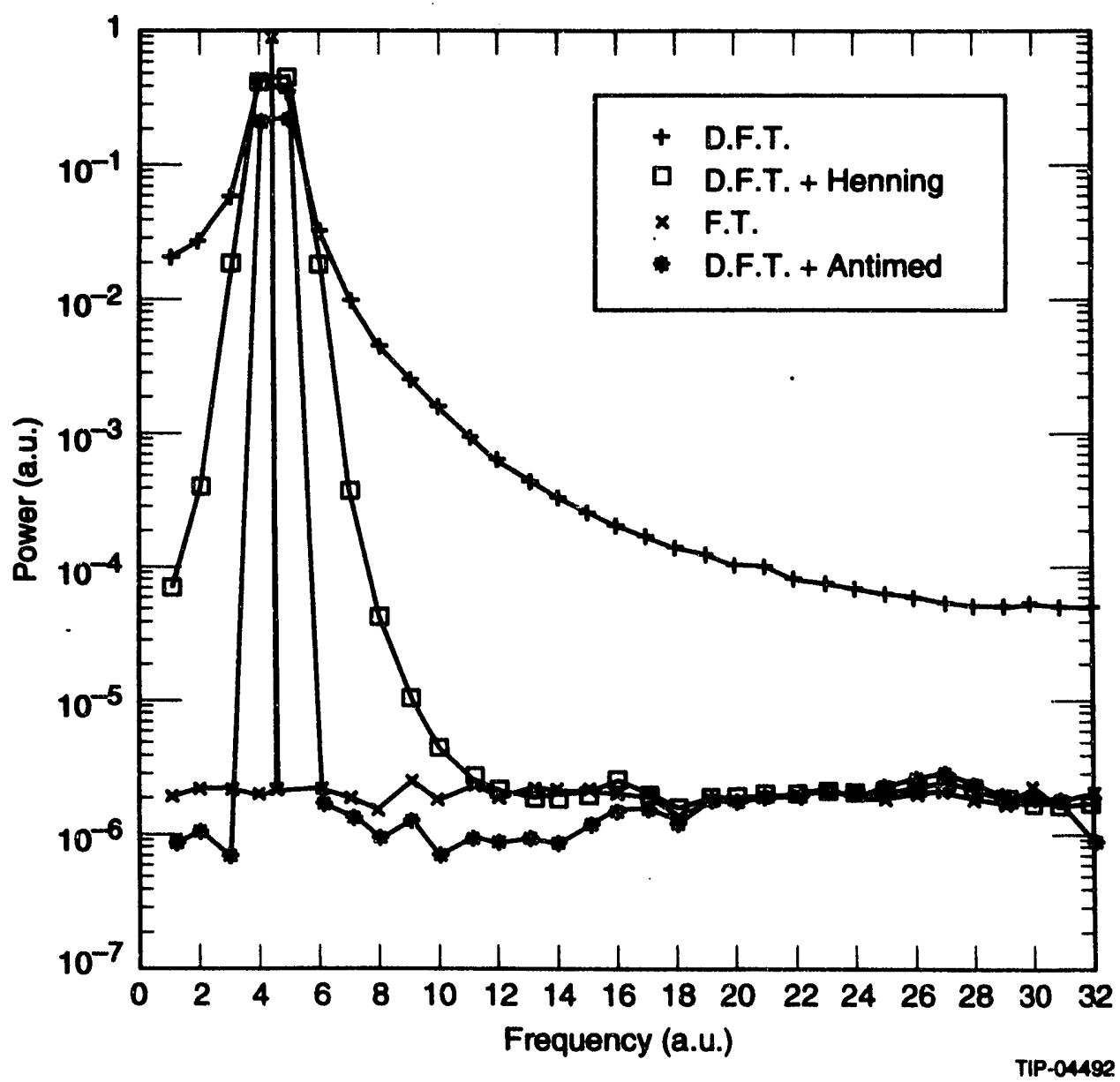

Figure A.1. Comparison of Different Digital Filters. 

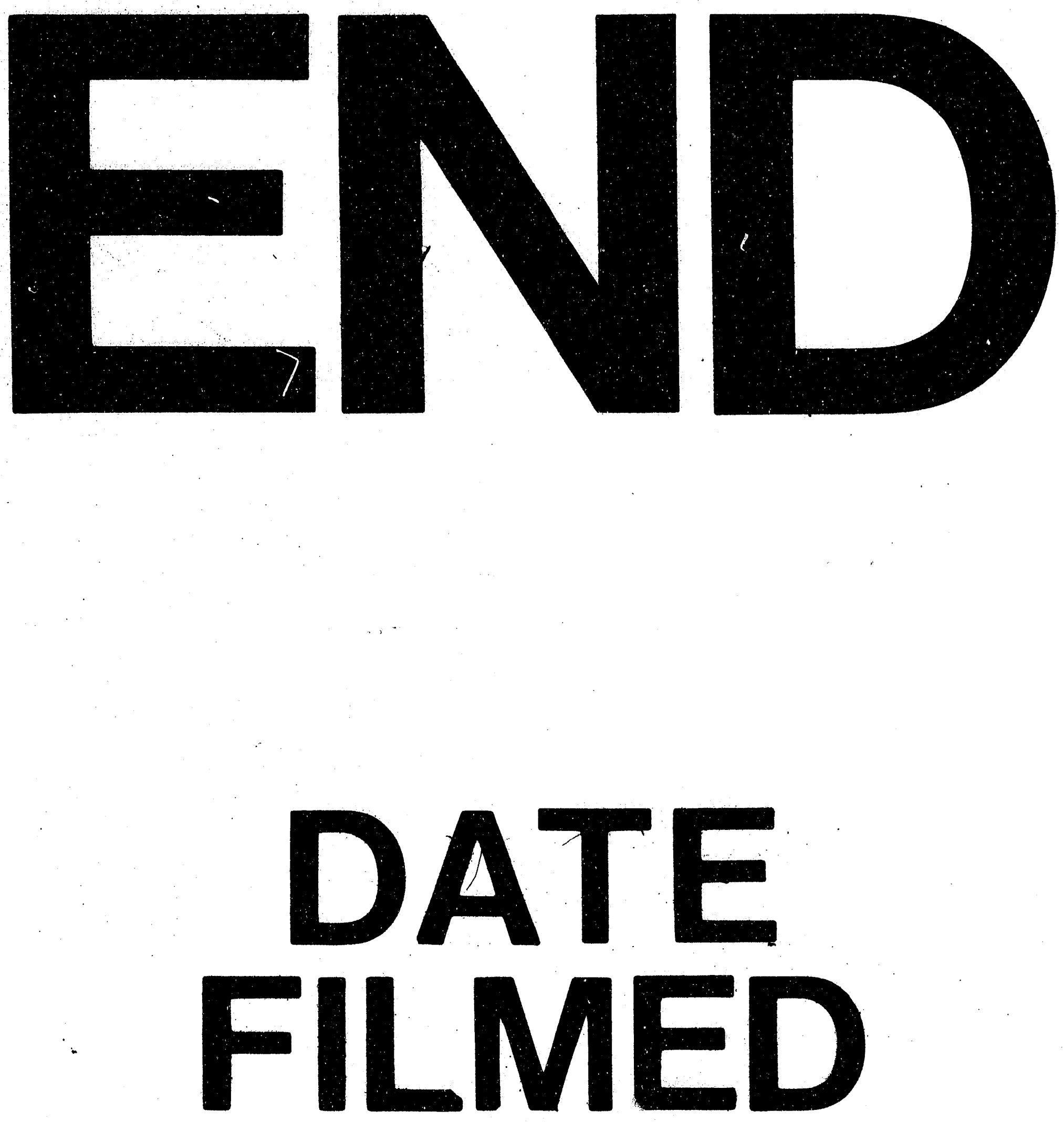

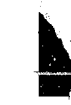

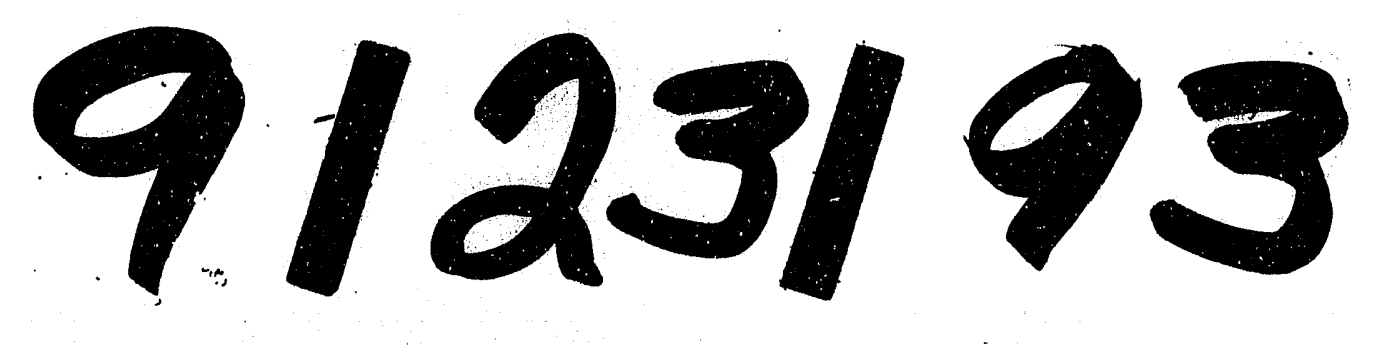


